\title{
Long-Term Financial Contracts in an Endowment Economy of the Eggertsson-Krugman Model
}

\author{
Avner Bar-Ilan*, Yasmin Peled \\ Department of Economics University of Haifa \\ Email: bar-ilan@econ.haifa.ac.il
}

\begin{abstract}
This paper extends the endowment economy model of Eggertsson and Krugman (2012) by allowing for various durations of financial contracts. This extension might change the way that monetary policy affects the economy. Lower nominal interest rate appreciates the real value of outstanding long term debt and forces indebted consumers to cut their consumption. This contractionary effect partially offsets the standard expansionary effect of low interest rates. Longer financial contracts make this unconventional offsetting larger. The expansionary effect of commitment to future inflation, on the other hand, does not depend on the length of financial contracts.
\end{abstract}

Keywords: Deleveraging, debt deflation, monetary policy.

\section{Introduction}

Household debt plays a significant role in the studies of the current Great Recession. According to Hall (2011), tightening of household borrowing constraint forced borrowers to reduce their consumption drastically and generated a deleveraging shock that pushed the economy toward a recession. Ueda (2012) argues that a major lesson from the recent experience of the U.S. and Japan is that deleveraging can generate significant negative macroeconomic externalities.

Changes in the real value of outstanding debt are crucial in understanding this channel. Falling prices increase the real burden of nominal debt, leading to a vicious circle identified by Fisher (1933) in the context of the Great Depression. The current relevance of this "Fisherian" debt deflation is emphasized by Eggertsson and Krugman (2012), denoted here as EK.

The focus of this paper is on unanticipated changes in nominal interest rates as another channel that affects the real value of debt. Falling interest rates raise the value of outstanding debt and force indebted consumers to deleverage and cut their consumption. In order to study this effect we extend the endowment economy part of the EK model by introducing financial contracts of various lengths: short run contracts are one period long, two period contracts, and long contracts in the form of perpetuities.

When financial contracts are short, nominal interest rate impacts the economy in a standard way. Higher nominal rate, for a given real rate, implies higher expected inflation and lower price level. This is Fisherian debt deflation that raises the real value of the outstanding debt, reduces consumption of the borrower and lowers the real interest rate to increase consumption of the lender.

When contracts are long, on the other hand, there is another channel by which interest rates affect the economy. This channel works in the opposite direction than the standard one as higher nominal rate depreciates the real value of outstanding debt. This allows the borrower to consume more and consequently lowers saver's consumption and raises the real interest rate. The overall effect on the economy is therefore potentially ambiguous. We show that the standard contractionary effect of higher interest rates is still dominant, but it becomes weaker as the financial contract becomes longer. We therefore conclude that the distribution and duration of debt within the economy plays a major role in defining the quantitative effect of monetary policy.

The effect of commitment to future inflation does not depend on distribution of the debt. Future inflation tends to mitigate the Fisherian deflation that follows a deleveraging shock. This expansionary effect takes place both when contracts are short and long. However, as often discussed in the literature, commitment to future inflation suffers from problem of dynamic inconsistency.

The macroeconomic implications of liquidity constrained consumers are the focus of other recent papers. Iacoviello (2005) introduces collateral constraints tied to housing values and stresses the significance of nominal debt contracts and debt inflation. Monacelli (2009) shows that introduction of a 
borrowing constraint helps in reconciling his two-sector model with empirical evidence. Mian and Sufi (2011) document the empirical contribution of home equity based borrowing to the process of defaulting and deleveraging. The response of monetary policy to credit spreads is discussed by Curdia and Woodford (2010). The implications of the presence of liquidity constraints to the understanding of monetary policy are discussed also by Kajuth (2008) and Albonico and Rossi (2011). ${ }^{1}$

The structure of the paper is as follows. Section 2 presents and solves the model with three lengths of contracts. The results are analyzed in Section 3.

\section{The Model and Its Solution}

\subsection{One Period Contracts}

A consumer maximizes the utility function $E_{t} \sum_{j=0}^{\infty} \beta(i)^{j} \log C_{t+j}(i)$, where $\beta(s) \equiv \beta>\beta(b)$. The parameter $\mathrm{i}=\mathrm{s}$ denotes the patient consumer ("saver") and the impatient consumer, the "borrower", is denoted by b.

A loan $L_{t}$ is a nominal loan with a real value $L_{t} / P_{t}$ that charges nominal interest rate denoted by $i$. $L_{t}>0$ denotes borrowing and $L_{t}<0$ is lending, and it cannot exceed the upper bound $D^{\max }, L_{t} \leq D^{\max } .^{2}$ $Y / 2$ is the per-period endowment that each of the two representative agents gets and the real interest rate is denoted by $r$. The budget constraint is, $\frac{L_{t}}{P_{t}}=\left(1+r_{t-1}\right) \frac{L_{t-1}}{P_{t-1}}-\frac{Y}{2}+C_{t}$.

Substitution of $1+r_{t-1}=\left(1+i_{t-1}\right)\left(P_{t-1} / P_{t}\right)$ into this equation gives, $\frac{L_{t}}{P_{t}}=\left(1+i_{t-1}\right) \frac{L_{t-1}}{P_{t}}-\frac{Y}{2}+C_{t}$.

Unanticipated deflationary shock, $P_{t}<E_{t-1} P_{t}$, increases the real value of the outstanding debt $L_{t-1}$ and allows for a lower current loan $L_{t} / P_{t}$ and consequently lower borrower's consumption, a "Fisherian" debt deflation.

Consumption levels of the borrower and the saver are given by

$$
\begin{aligned}
& C_{t}^{b}=\frac{Y}{2}+\frac{L_{t}}{P_{t}}-\left(1+i_{t-1}\right) \frac{L_{t-1}}{P_{t}} \\
& C_{t}^{s}=\frac{Y}{2}-\frac{L_{t}}{P_{t}}+\left(1+i_{t-1}\right) \frac{L_{t-1}}{P_{t}}
\end{aligned}
$$

At the steady state the borrower borrows up to the limit $L_{t} / P_{t}=L_{t-1} / P_{t-1}=L / P=D^{\max }$. As consumption and the price level are also constant, the Euler equation $\frac{1}{C_{t}^{s}}=\left(1+r_{t}\right) \beta E_{t}\left(\frac{1}{C_{t+1}^{s}}\right)$ yields $r=i=\frac{1-\beta}{\beta}, C^{b}=\frac{Y}{2}-i \frac{L}{P}=\frac{Y}{2}-i D^{\max }=\frac{Y}{2}-\frac{1-\beta}{\beta} D^{\max }, C^{s}=\frac{Y}{2}+i \frac{L}{P}=\frac{Y}{2}+i D^{\max }=\frac{Y}{2}+\frac{1-\beta}{\beta} D^{\max }$.

Suppose that the economy was in a steady state with a constant price level denoted by $P_{0}$ and with $D^{\max }$ equal to $D^{\text {high }}$. At the start of period $t$ a deleveraging shock hits the economy as $D^{\max }$ falls permanently and unexpectedly to $D^{\text {low }}<D^{\text {high }}$. That is, the period-t deleveraging shock reduced the real debt limit from $\frac{L_{t-1}}{P_{t-1}}=\frac{L_{t-1}}{P_{0}}=D^{\text {high }}$ to $\frac{L_{t}}{P_{t}}=D^{\text {low }}$. As $i_{t-1}=i=(1-\beta) / \beta$, the consumption levels right

${ }^{1}$ Related literature deals with other real consequences of debt maturity. Maturity of corporate debt is an important factor for the problem of debt overhang that reduces the incentive of firms to make real investments. Diamond and He (2012) is a recent example.

${ }^{2} \mathrm{EK}$ defines the debt limit as future value (inclusive of next period interest rate payments) and here the debt limit is defined in present value terms, to correspond to the definition of the debt limit in longer term financial contracts. 
after the shock are $C_{t}^{b}=\frac{Y}{2}+D^{\text {low }}-\frac{D^{\text {high }}}{\beta}\left(\frac{P_{0}}{P_{t}}\right), C_{t}^{s}=\frac{Y}{2}-D^{\text {low }}+\frac{D^{\text {high }}}{\beta}\left(\frac{P_{0}}{P_{t}}\right)$.

We adopt now the simplifying assumption made in EK of dividing periods in "short run" and "long run". Period $t$ is the short run while in the long run, denoted by $L$, the economy converges to the new steady state when the debt is equal to the lower limit $D^{\text {low }}$ to get $C_{L}^{b}=\frac{Y}{2}-\frac{1-\beta}{\beta} D^{\text {low }}$, $C_{L}^{s}=\frac{Y}{2}+\frac{1-\beta}{\beta} D^{l o w}$

The Euler equation that connects the short run, period $t$, and the long run is

$$
\beta\left(1+r_{t}\right)=\beta\left(1+i_{t}\right) \frac{P_{t}}{P_{L}}=\frac{C_{L}^{s}}{C_{t}^{s}}=\frac{\frac{Y}{2}+\frac{1-\beta}{\beta} D^{\text {low }}}{\frac{Y}{2}-D^{\text {low }}+\frac{D^{\text {high }}}{\beta}\left(\frac{P_{0}}{P_{t}}\right)} .
$$

The constant long run price level $P_{L}$ is anticipated and $\left(1+r_{t}\right)=\left(1+i_{t}\right) \frac{P_{t}}{P_{L}}$.

\section{$2.2 \quad$ Two Period Contracts}

A consumer maximizes the same utility function as with one-period contracts subject to a budget constraint $\frac{L_{t}}{P_{t}}=\left(1+r_{t-2,2}\right)^{2} \frac{L_{t-2}}{P_{t-2}}-\frac{Y}{2}+C_{t}$.

$\mathrm{L}_{\mathrm{t}}$ is a zero-coupon loan borrowed at period $\mathrm{t}$ for two periods at the nominal interest rate $i_{t, 2}$. $\left(1+r_{t-2,2}\right)^{2}=\frac{\left(1+i_{t-2,2}\right)^{2}}{P_{t} / P_{t-2}}$ is the ex-post real interest rate when the nominal interest rate $\mathrm{i}_{\mathrm{t}-2,2}$ is nominally fixed for the two periods of the contract. This gives, $\frac{L_{t}}{P_{t}}=\left(1+i_{t-2,2}\right)^{2} \frac{L_{t-2}}{P_{t}}-\frac{Y}{2}+C_{t}$.

The outstanding debt $D_{t}$ at period $t$, in present value terms, is $D_{t}=\frac{L_{t-1}\left(1+i_{t-1,2}\right)^{2}}{P_{t}\left(1+i_{t, 1}\right)}+\frac{L_{t}}{P_{t}} \leq D^{\max }$, where $D^{\max }$ denotes the borrowing limit, set in real terms.

The steady-state solution, when the impatient consumer loans up to the limit, is

$$
\frac{L_{t}}{P_{t}}=D^{\max }-\frac{L_{t-1}\left(1+i_{t-1,2}\right)^{2}}{P_{t}\left(1+i_{t, 1}\right)} \text {. }
$$

In addition to Fisherian debt deflation, we observe here also the effect of unanticipated interest rate drop on appreciating the real value of outstanding debt, allowing for lower current borrowing and borrower's consumption.

At the steady state loans, interest rates, and prices are constant to give $\frac{L}{P}=\frac{D^{\max }}{2+i}, C^{b}=\frac{Y}{2}-i D^{\max }$, $C^{s}=\frac{Y}{2}+i D^{\max }$.

The Euler equation holds for the unconstrained, patient consumer to give $i=r=\frac{1-\beta}{\beta}$, $\frac{L}{P}=\frac{\beta}{1+\beta} D^{\max }, C^{b}=\frac{Y}{2}-\frac{1-\beta}{\beta} D^{\max }, C^{s}=\frac{Y}{2}+\frac{1-\beta}{\beta} D^{\max }$. 
Before the period-t deleveraging shock the economy was in a steady state with $D^{\max }=D^{\text {high }}$ and $\frac{L_{t-1}}{P_{t-1}}=\frac{L_{t-2}}{P_{t-2}}=\frac{L}{P_{0}}=\frac{\beta}{1+\beta} D^{h i g h} \quad$ where $\quad P_{0}$ is the constant price level before the shock and $1+i_{t-2,2}=1+i_{t-1,2}=\frac{1}{\beta}$.

At the start of period t $D^{\text {max }}$ falls from $D^{\text {high }}$ to $D^{\text {low }}<D^{\text {high }}$. The short run, right after the deleveraging shock, is

$$
\begin{aligned}
& \frac{L_{t}}{P_{t}}=D^{\text {low }}-\frac{D^{\text {high }}}{\beta(1+\beta)}\left(\frac{P_{0}}{P_{t}}\right)\left(\frac{1}{1+i_{t, 1}}\right), C_{t}^{b}=\frac{Y}{2}+D^{\text {low }}-\frac{D^{\text {high }}}{\beta(1+\beta)}\left(\frac{P_{0}}{P_{t}}\right)\left(\frac{2+i_{t, 1}}{1+i_{t, 1}}\right), \\
& C_{t}^{s}=\frac{Y}{2}-D^{\text {low }}+\frac{D^{\text {high }}}{\beta(1+\beta)}\left(\frac{P_{0}}{P_{t}}\right)\left(\frac{2+i_{t, 1}}{1+i_{t, 1}}\right) .
\end{aligned}
$$

The long run consumption of the patient consumer is, $C_{L}^{s}=\frac{Y}{2}+\frac{1-\beta}{\beta} D^{\text {low }}$.

Adopting again the assumption of dividing periods to short run, period $t$, and long run, when the economy converges to the new steady state, and interest rate $i_{t}=i_{t, 1}$ that connects the two periods, yields the Euler equation $\beta\left(1+r_{t}\right)=\beta\left(1+i_{t}\right) \frac{P_{t}}{P_{L}}=\frac{C_{L}^{s}}{C_{t}^{s}}=\frac{\frac{Y}{2}+\frac{1-\beta}{\beta} D^{\text {low }}}{\frac{Y}{2}-D^{\text {low }}+\frac{D^{\text {high }}}{\beta(1+\beta)}\left(\frac{P_{0}}{P_{t}}\right)\left(\frac{2+i_{t}}{1+i_{t}}\right)}$.

\subsection{Long Term Contracts}

The debt is very long in the form of nominal perpetuities. Each period the borrower has to pay z dollars to the lender. The real outstanding debt is $D_{t}=\frac{z}{P_{t} i_{t}} \leq D^{\max }$. The budget constraint of the borrower and lender, respectively, are $C_{t}^{b}=\frac{Y}{2}-\frac{z}{P_{t}}+\frac{L_{t}}{P_{t}}, C_{t}^{s}=\frac{Y}{2}+\frac{z}{P_{t}}-\frac{L_{t}}{P_{t}}$, where $L_{t}>0$ is a new loan and $L_{t}<0$ is a margin call to reduce the outstanding debt.

In a steady state with $D^{\max }=D^{\text {high }}$, before the shock, then $L=0$ and the Euler equation gives $i=r=(1-\beta) / \beta$. The other variables are $\frac{z}{P_{0}}=\frac{1-\beta}{\beta} D^{h i g h}$, where $P_{0}$ is the constant price level, $C^{b}=\frac{Y}{2}-\frac{1-\beta}{\beta} D^{h i g h}, C^{s}=\frac{Y}{2}+\frac{1-\beta}{\beta} D^{h i g h}$.

Once the deleveraging shock $\mathrm{D}^{\text {low }}$ hits the economy, the real value of the outstanding debt becomes $\frac{z}{P_{t}\left(1+i_{t}\right)}+\frac{z}{P_{t}\left(1+i_{t}\right)(1+i)}+\ldots \frac{z}{P_{t}\left(1+i_{t}\right)(1+i)^{k}}+\ldots=\frac{z}{P_{t}\left(1+i_{t}\right)}\left(1+\frac{1}{1+i}+\ldots\right)=\frac{z}{P_{t}\left(1+i_{t}\right)}\left(\frac{1+i}{i}\right)=\frac{P_{0}}{P_{t}} \frac{1+i}{1+i_{t}} D^{\text {high }}$. The last equation is derived from $z=r P_{0} D^{\text {high }}=i P_{0} D^{\text {high }}$ and $i_{t}$ is the interest rate that connects the short run, period $t$, and the long run steady state.

$$
\begin{aligned}
& \frac{L_{t}}{P_{t}}=D^{\text {low }}-\frac{D^{\text {high }}}{\beta}\left(\frac{P_{0}}{P_{t}}\right)\left(\frac{1}{1+i_{t, 1}}\right), C_{t}^{b}=\frac{Y}{2}-\frac{z}{P_{t}}+\frac{L_{t}}{P_{t}}=\frac{Y}{2}+D^{\text {low }}-D^{\text {high }} \frac{P_{0}}{P_{t}}\left(\frac{2+i_{t}}{\beta\left(1+i_{t}\right)}-1\right) \\
& C_{t}^{s}=\frac{Y}{2}-D^{\text {low }}+D^{\text {high }} \frac{P_{0}}{P_{t}}\left(\frac{2+i_{t}}{\beta\left(1+i_{t}\right)}-1\right)
\end{aligned}
$$

The Euler equation, connecting the short run and the long run steady state, is 


$$
\beta\left(1+r_{t}\right)=\beta\left(1+i_{t}\right) \frac{P_{t}}{P_{L}}=\frac{\frac{Y}{2}+\frac{1-\beta}{\beta} D^{\text {low }}}{\frac{Y}{2}-D^{\text {low }}+D^{\text {high }} \frac{P_{0}}{P_{t}}\left(\frac{2+i_{t}}{\beta\left(1+i_{t}\right)}-1\right)}
$$

\section{$3 \quad$ Results}

We can now study the effect of monetary policy and the length of financial contracts on the economy. Monetary policy determines the long run price $P_{L}$ and the nominal interest rate $i_{t}$, while the short run price level $P_{t}$ and the real interest rate $r_{t}$ are endogenous variables determined by the Euler equation.

It is easy to prove that the derivatives of $r_{t}, P_{t}$, and $C_{t}^{b}$ with respect to $P_{L}$ are all positive. This holds for one period, two period, and very long financial contracts. Commitment to higher future price level implies that a smaller drop in the short run price level $P_{t}$ is required in order to generate the expected inflation that is compatible with a certain real interest rate. The higher $P_{t}$ leads to less Fisherian deflation and consequently has expansionary effect on the consumption of the borrower. This implies smaller consumption of the saver and therefore higher real interest rate. However, as EK emphasize, a commitment to future inflation is dynamically inconsistent.

The effect of nominal interest rate, on the other hand, potentially depends on the financial structure of the economy as follows. Higher nominal interest rate implies that, for a given real interest rate, the expected inflation should rise and therefore the price level $P_{t}$ should drop. This drop is Fisherian debt deflation that demonstrates the standard contractionary effect on the consumption of the borrower. In equilibrium the consumption of the lender increases and this is achieved by a lower real interest rate. When financial contracts are short, one-period contracts, this is the only effect of the nominal interest rate. Consequently it can be shown analytically that for one period contracts the derivatives of $r_{t}, P_{t}$, and $C_{t}^{b}$ with respect to $i_{t}$ are all negative. Figure 1 demonstrates the negative response of $C_{t}^{b}$ to the nominal interest rate after a deleveraging shock.

When financial contracts are longer than one period, there is additional channel by which the nominal interest rate affects the economy. The impact, direct effect of unanticipated higher nominal rate is to lower the real burden of the outstanding debt, allowing the borrower to consume more. This should tend to raise the three variables $r_{t}, P_{t}$, and $C_{t}^{b}$, counteracting the Fisherian deflation effect to give potentially ambiguous effect of nominal interest rates on the economy. However, it can be shown analytically that for both two period and very long contracts the latter effect dominates to give lower $r_{t}$, $P_{t}$, and $C_{t}^{b}$ when the nominal interest rate rises. This is depicted in Figure 2 for two-period contracts and in Figure 3 for very long contracts. Still, the derivatives of $r_{t}, P_{t}$, and $C_{t}^{b}$ with respect to $i_{t}$ are negative but smaller, in absolute value, the longer the contract as the lower real debt partially offsets the standard effect of the Fisherian deflation. The smaller effect of $i_{t}$ on $C_{t}^{b}$ the longer the contract is clearly depicted in comparing the three figures, Figures 1-3. (The three interest rate lines that correspond to long term contracts merge and cannot be differentiated when the range of $D^{\text {low }}$ is as in Figures 1 and 2, $50 \leq D^{\text {low }}<100$. This is why the range of $D^{\text {low }}$ in Figure 3 is smaller.) The same phenomenon is demonstrated also in Figures 4-6. Increasing the nominal interest rate from 0 (Figure 4) to $(1-\beta) / \beta=0.02$ (Figure 5) to $2(1-\beta) / \beta=0.04$ (Figure 6) reduces the real interest rate $\mathrm{r}_{\mathrm{t}}$ less the longer the contract. As a result the ordering of $r_{t}$ in terms of its size changes from Figure 4 where $r_{t}$ (one period $)>r_{t}($ two period $)>r_{t}($ perpetuity $)$ to Figure 5 where $r_{t}($ one period $)=r_{t}($ two period $)=r_{t}($ perpetuity $)$ to $r_{t}($ one period $)<r_{t}($ two period $)<r_{t}$ (perpetuity) in Figure 6 .

\section{Conclusion}

Monetary policy in recent years, starting with the financial crisis of 2008, is very expansionary in the 
U.S., Europe, and Japan. This policy is characterized by very low nominal interest rates and commitment to future loose monetary policy, "forward guidance," a commitment to future low interest rates and higher inflation. This paper studies the robustness of the two aspects of this policy to the structure of financial contracts within the Eggertsson-Krugman model.

We find that future guidance is an efficient expansionary tool, irrespective of the structure of financial contracts. On the other hand, the standard effect of short term nominal interest rates as a monetary policy tool is weaker the longer the financial contracts in the economy are. The rationale of this result is that low nominal interest rates increase the real burden of outstanding debt and force indebted consumers to cut consumption. The longer financial contracts, the stronger is this unconventional channel.

This result has practical implications. In his influential empirical paper on the robustness and efficiency of monetary policy, Taylor (1999) concludes that there is a spectrum of optimal rules, depending on the structure of the economy. In Taylor's case, the structure is mainly the wage-price determination, but our conclusion highlights the importance of financial structure to the efficacy of monetary policy.

Acknowledgments. We thank Micha Ben-Gad, Baruch Gliksberg, Al Gustman, Meir Kohn and Nancy Marion for helpful discussions and comments.

\section{References}

1. Albonico, Alice and Lorenza Rossi. 2011. "Policy Games with Liquidity Constrained Consumers." University of Pavia working paper.

2. Curdia, Vasco and Michael Woodford. 2010. "Credit Spreads and Monetary Policy." Journal of Money, Credit, and Banking 42(6): 3-35.

3. Diamond, Douglas W. and Zhiguo He. 2012. "A Theory of Debt Maturity: The Long and Short of Debt Overhang." University of Chicago working paper.

4. Eggertsson, Gauti B. and Paul Krugman. 2012. "Debt, Deleveraging, and the Liquidity Trap: A Fisher-MinskyKoo Approach." Quarterly Journal of Economics 127(3): 1469-1513.

5. Fisher, Irving. 1933. "The Debt-Deflation Theory of Great Depressions." Econometrica 1(4): 337-357.

6. Hall, Robert E. 2011. "The Long Slump." American Economic Review, 101(2): 431-69.

7. Iacoviello, Matteo. 2005. "House Prices, Borrowing Constraints, and Monetary Policy in the Business Cycle." American Economic Review 95(3): 739-64.

8. Kajuth, Florian. 2008. "The Role of Liquidity Constraints in the Response of Monetary Policy to House Prices." Deutsche Bundesbank working paper.

9. Mian, Atif R. and Amir Sufi.2011. "House Prices, Home Equity-Based Borrowing, and the U.S. Household Leverage Crisis." American Economic Review 101(5): 2132-56.

10.Monacelli, Tommaso. 2009. "New Keynesian Models, Durable Goods, and Collateral Constraints." Journal of Monetary Economics 56: 242-54.

11.Taylor, John B. 1999. "The Robustness and Efficiency of Monetary Policy Rules as Guidance for Interest Rate Setting by the European Central Bank." Journal of Monetary Economics 43: 655-79.

12.Ueda, Kazuo. 2012. "Deleveraging and Monetary Policy: Japan Since the 1990s and the United States Since 2007." Journal of Economic Perspectives 26 (3): 177-202. 


\section{Appendix: Figures}

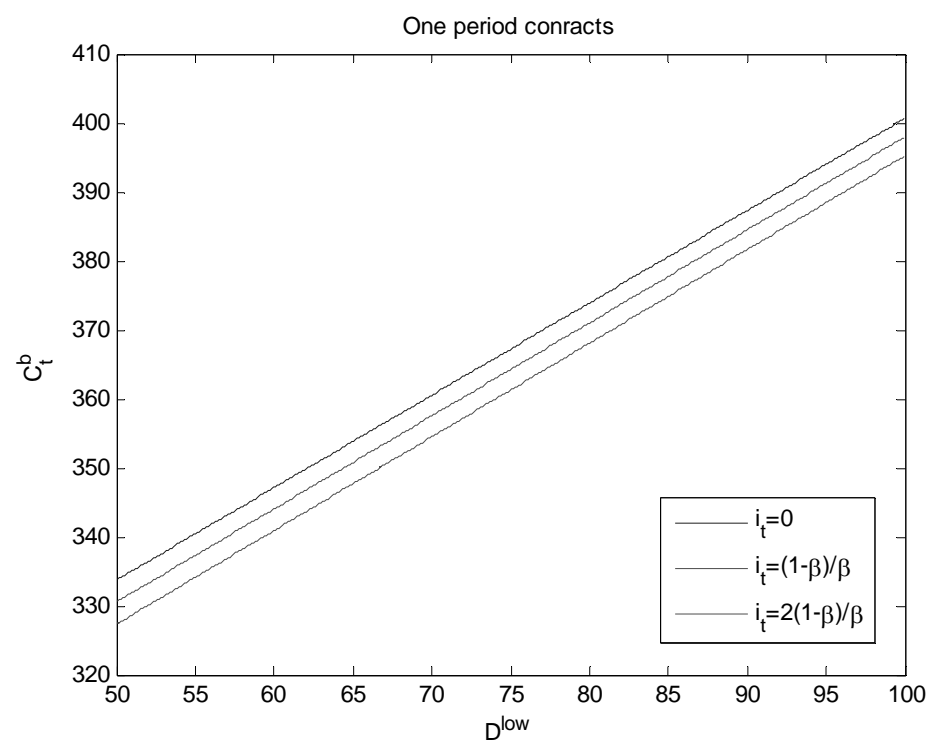

Figure 1. Consumption of the borrower $C_{t}^{b}$ following a deleveraging shock as a function of $D^{\text {low }}$ with one-period contracts. Parameter values are $Y=800, D^{\text {high }}=100, \beta=0.98, P_{0}=P_{L}=1$.

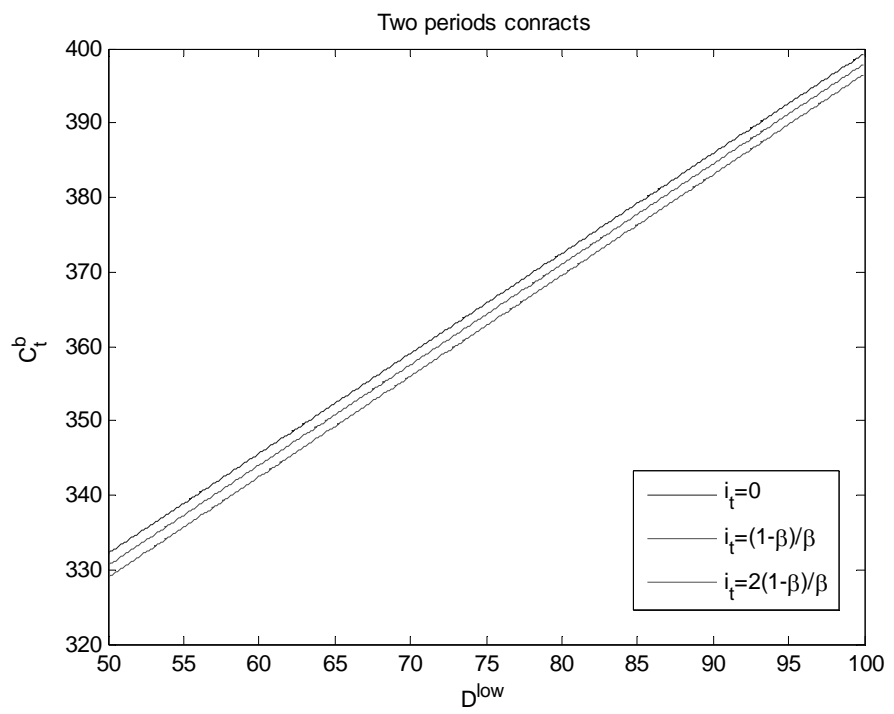

Figure 2. Consumption of the borrower $C_{t}^{b}$ following a deleveraging shock as a function of Dlow with two-period contracts. Parameter values are $\mathrm{Y}=800$, Dhigh $=100, \beta=0.98, P_{0}=P_{L}=1$. 


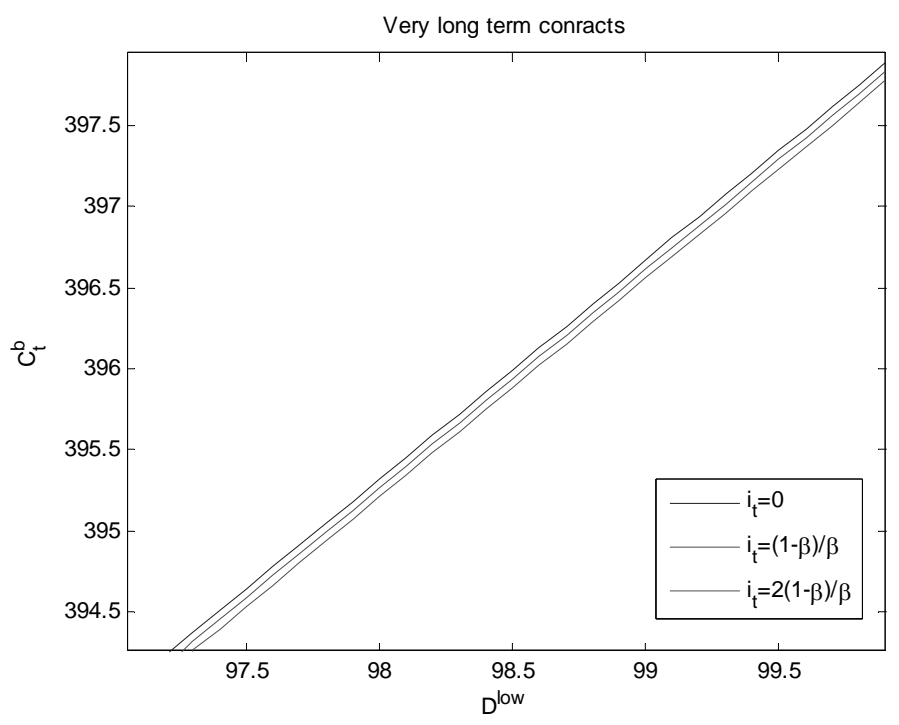

Figure 3.: Consumption of the borrower $C_{t}^{b}$ following a deleveraging shock as a function of Dlow with very long contracts (perpetuities). Parameter values are $\mathrm{Y}=800$, Dhigh $=100, \beta=0.98, P_{0}=P_{L}=1$.

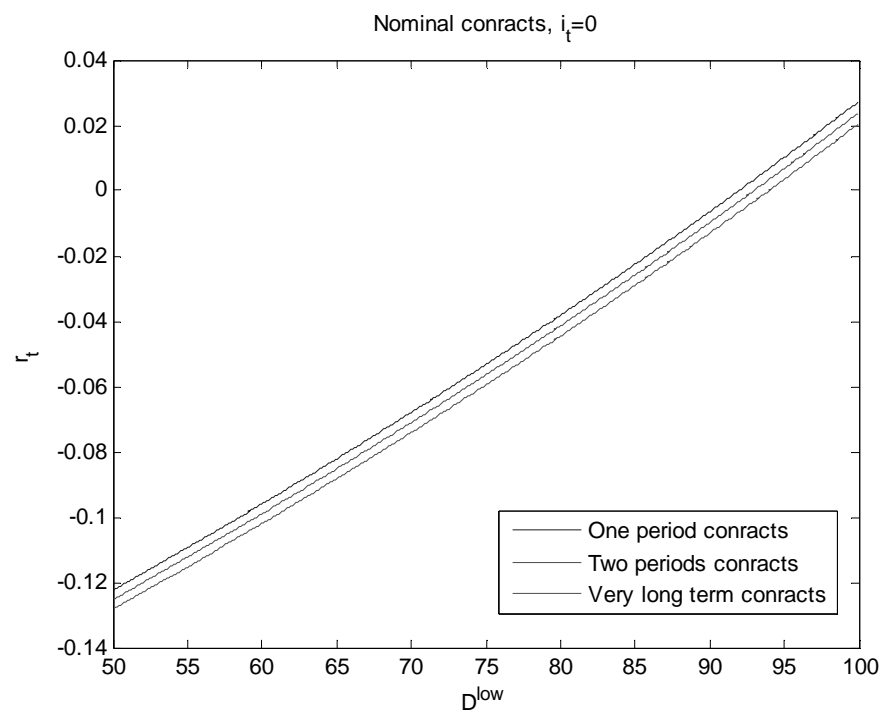

Figure 4. Real interest rate $r_{t}$ following a deleveraging shock as a function of Dlow with nominal interest rate $i_{t}=0$. Parameter values are $\mathrm{Y}=800$, Dhigh $=100, \beta=0.98, P_{0}=P_{L}=1$. 


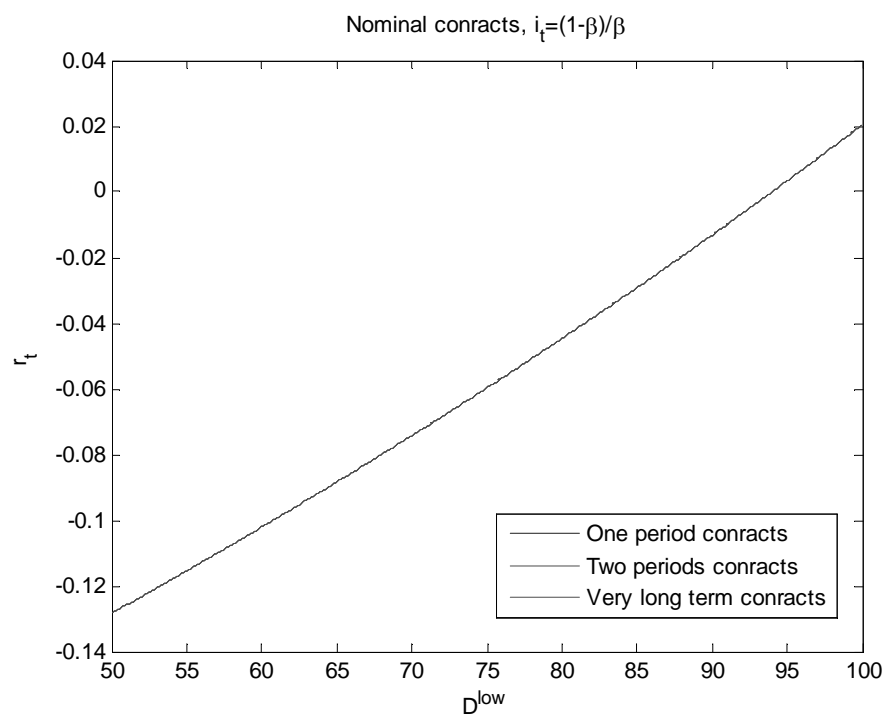

Figure 5. Real interest rate $r_{t}$ following a deleveraging shock as a function of Dlow with nominal interest rate $i_{t}=(1-\beta) / \beta$. Parameter values are $\mathrm{Y}=800$, Dhigh $=100, \beta=0.98, P_{0}=P_{L}=1$.

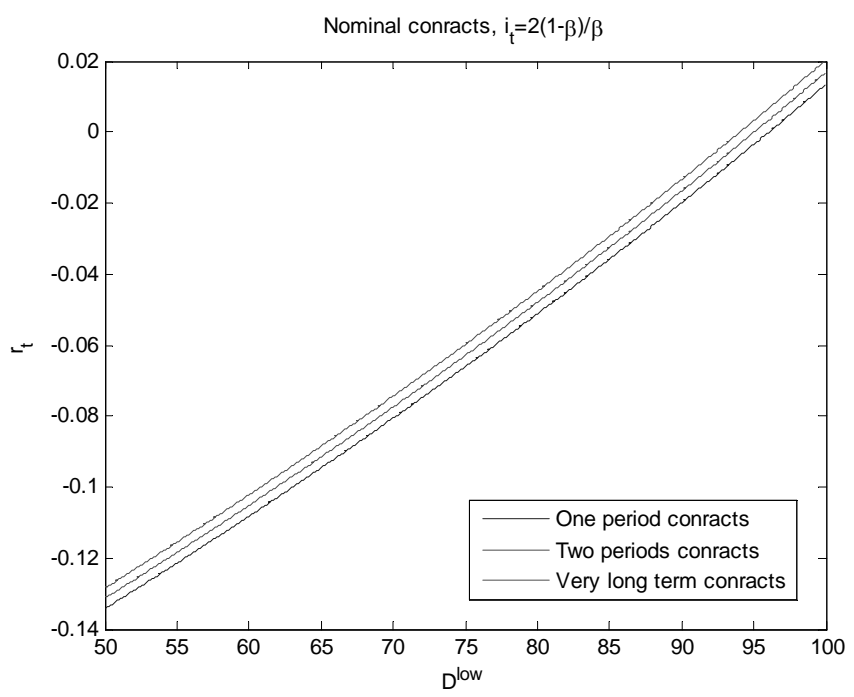

Figure 6. Real interest rate $r_{t}$ following a deleveraging shock as a function of Dlow with nominal interest rate $i_{t}=2(1-\beta) / \beta$. Parameter values are $\mathrm{Y}=800$, Dhigh $=100, \beta=0.98, P_{0}=P_{L}=1$. 